\title{
General Overview of TBLT and Its Applicability To The University English Classrooms in Japan
}

\author{
Fuyu Shimomura ${ }^{1, *}$ \\ ${ }^{1}$ General Education Center, Kyoto Sangyo University, Kamigamo-Motoyama, Kita-ward, \\ Kyoto, 603-8555, Japan \\ *Correspondence: General Education Center, Kyoto Sangyo University, Kamigamo- \\ Motoyama, Kita-ward, Kyoto, 603-8555, Japan. Tel: 75-705-1408 (ext. 3951) E-mail: \\ fuyu@cc.kyoto-su.ac.jp
}

Received: September 26, 2014 Accepted: October 20, 2014 Published: November 18, 2014 doi:10.5296/ije.v6i4.6361 URL: http://dx.doi.org/10.5296/ije.v6i4.6361

\begin{abstract}
Instead of the formerly dominant PPP (Presentation-Practice-Production) model, the TBLT (Task-Based Language Teaching) model has gained attention in SLA researches and practices during the last two decades. To better understand the TBLT model and its efficacy in the sociocultural contexts of university English classrooms in Japan, this paper reviews the major TBLT publications and explores why TBLT is popular, analyzes its strengths and limitations, explores its theoretical background, and considers the Japan-specific sociocultural factors that need to be considered when implementing the model. At the end, the paper also identifies the areas of the model that require further researches.
\end{abstract}

Keywords: TBLT, Japan, university, English teaching 


\section{Shifts toward the TBLT Model from the PPP Model}

There are a variety of pedagogies for English language teaching. Some scholars have already noted that there have been some shifts observed in the trends of these pedagogies over the years in university English classrooms (Dickinson, 2010; Ellis, 2000; Hosseini \& Rahbar, 2012; Nunan, 2004). One of these frequently observed trends is the recent shift to the TBLT (Task-Based Language Teaching) model from the formerly dominant PPP (Presentation-Practice-Production) model in ELT research and practice around the world. The PPP model was predominant in the field until the TBLT model started gaining attention in the last decade of the 20 $0^{\text {th }}$ century (Dickinson, 2010; Ellis, 2000; Nunan, 2004; Nunn, 2001; Wicking, 2009).

As the name indicates, in the PPP model, teachers present the model of grammatical knowledge or grammatical knowledge, and students practice and learn how to produce particular pronunciation or grammatical knowledge. The model characterizes "the pre-selected items, controlled repetition, and direct instruction of grammar", which emphasizes form-focused activities such as patterned repeating practices or drills (Hosseini \& Rahbar, 2012, p.254). Given its form- and grammar-focused nature, it has already been noted that the model has a risk that both learners and teachers will be "overtly concerned with grammatical form, even during the 'production stage' when the focus should be on meaningful language use" (Dickinson, 2010, p.13). Therefore, it is noted that the PPP model tends to help students acquire grammatical knowledge rather than communication competence. Dickinson (2010) even reports that in the worst case there have been some instances in his classrooms in which "learners become so obsessed with accurately producing the target language that no meaningful communication takes place at all" (Dickinson, 2010, p.13). This indicates that using the PPP model has a potential risk of leading students to acquire too much grammar and making them less likely to attain communicative competence.

Furthermore, some scholars also attribute the transition from the PPP model to TBLT model to the shift in conceptualization of learning itself. For instance, Nunan (2004) identifies that learning used to be identified as "a process of habitual formation". Given that the PPP model is based on imitating the presented model and repeating practices until learners acquire particular skills, the model appears a good match with the definition of learning (p.7). After the Vygotsky's learning theory became prevalent, however, many learning scientists have started to perceive learning as social processes that "cognitive processes [learners] engage in as they learn are seen as fundamentally important" to better understand the effective learning processes (Nunan, 2004, p.7). In other words, the PPP model does not fit well with the trends of shifts in the perception of learning as social processes that became prevalent as the Vygotskyan approach became popular.

In sum, both the contents of learning and how students learn are nearly completely fixed in the PPP model, and therefore, the opportunities for teachers to improvise content and practice based on learners' needs are relatively few. Furthermore, the model could drive learners to focus too much on grammar and risk losing the opportunity to acquire communicative ability. In addition, the PPP model does not fit well with the trends of shifts in perception of learning. 
Accordingly, some scholars attribute this shift of the pedagogy from PPP to TBLT to the fact that using the PPP model may result in hindering acquisition of communicative competence, as PPP is too structurally fixed and grammar-focused, and less capable to attending to the students' specific learning needs, and the model focuses on the habitual development rather than cognitive processes that learners engage in. Given these limitations of the model, the TBLT has started gaining attentions and replacing the PPP model. The next chapter further explores TBLT and its strengths and limitations.

\section{What Tasks should be Used in TBLT?}

\subsection{Various definitions of tasks}

Whereas the PPP model, the TBLT model is considered helpful for acquiring communicative English as the model provides students to complete a variety of tasks requiring them to communicate in English. These tasks are defined in various ways. Nunan (1989) clarifies that the tasks need to be parts of classroom activities in which students understand, produce and communicate in English. Some scholars also emphasize that these tasks need to be completed only through the interactions among the learners, without the teachers' help (Lee, 2000; Turuk, 2008). These tasks in the pedagogy have been defined in various ways. Long (1985) defines task as "a piece of work undertaken for oneself or for others" and "the hundred and one thing people do in everyday life, at work, at play and in between" (p.89). Richards, et al. (1986) define task differently. According to Richards, et al (1986), task is:

an activity or action which is carried out as the result of processing or understanding language (i.e. as a response)...Tasks may or may not involve the production of language...The use of a variety of different kinds of tasks in language teaching is said to make language teaching more communicative...since it provides purposes for a classroom activity which goes beyond the practice of language for its own sake.

In these definitions, tasks themselves do not necessarily involve language use. However, if used in language teaching, these tasks help make the learning processes more communication oriented as learners need to understand instructions in L2 to complete tasks. Depending on the types of tasks, learners may need to produce words in L2 to accomplish the tasks. These definitions do not refer to the importance of learning objectives or procedures almost at all.

Breen (1987) provides an alternative definition of tasks. According to Breen (1987), task is "any structured language learning endeavor which has a particular objective, appropriate content, a specified working procedure, and a range of outcomes for those who undertake tasks" (p.23). Therefore, task need to be "a range of workplans which have the overall purposes of facilitating language learning" (p.23). In this definition, task is designed as something that needs to be purposefully designed to acquire particular language skills by completing the tasks in the specified procedures. Breen (1987), accordingly, addresses the importance of structures and procedures of the tasks as well as the expected learning outcome 
upon completion of these tasks.

Ellis (2003) further elaborates Breen (1987)'s definition of tasks. According to Ellis (2003), task is "a workplan that requires learners to process language pragmatically in order to achieve an outcome that can be evaluated in terms of whether the correct or appropriate propositional content has been conveyed" (p.16). Therefore, task need to "give primary attention to meaning" and "the design of tasks may predispose them to choose particular forms" (p.16). Nunan (2004) adds grammar acquisition to the definition of task. According to Nunan (2004), task is " a piece of classroom work that involves learners in comprehending, manipulating, producing or interacting in the target language while their attention is focused on mobilizing their grammatical knowledge in order to express meaning" (p.4). Although pedagogical tasks in the model have been defined in many ways, these definitions of tasks share a perspective that "pedagogical tasks involve communicative language use in which the user's attention is focused on meaning rather than grammatical form" (Nunan, 2004, p.4). In other words, the TBLT model is based on a direct method, and students learn English while using the language to complete tasks without focusing too much on grammar acquisition. In short, in the TBLT model, it is important to focus on what kind of meaning exchanges in L2 happen among learners and acquire communicative ability in L2 while completing these tasks.

\subsection{Subcategories among meaning-focused tasks}

There are varieties of definitions of "tasks" as indicated in the former section. These definitions also highlight the nature of the tasks that these tasks need to be meaning-focused. Some other scholars provide three subcategories among these meaning-focused tasks: 1) tasks that require two-way exchange information, 2) planned tasks and 3) closed tasks. Regarding tasks that require two-way exchange information, it is already pointed out that "two-way tasks produce more negotiation work and more useful negotiation work than one-way tasks" as one participant tends to control the procedures to accomplish the tasks in one-way negotiation tasks rather than all the participants engage in negotiation (Long, 1989, p.13). In other words, the tasks that require learners to engage in negotiation work in L2 seem more efficacious in acquiring language.

Planned tasks refer to the tasks that allow enough times for learners to plan their outputs. Planned tasks are considered helpful as some scholars have already identified that learners are more likely to show increased level of accuracy when outputting if they are allocated with enough time to plan their outputs (Foster \& Skehan, 1997; Skehan, 1998). It also is indicated that these planned tasks should be efficacious for Japanese learners given their inclination to be reluctant to produce L2 unless they are sure that their answers are correct (Wicking, 2009). Closed task refer to the tasks that "require participants to reach a single correct solution" (Wicking, 2009, p. 254). Some scholars identify that closed tasks generate more negotiation works among learners, and these negotiations such as clarification requests or confirmation checks tend to be more efficacious in acquiring language than communication observed in open tasks such as free conversation or debate (Long, 1989; Ellis, 1994). This means closed tasks have a potential to help learners acquiring language. 
Given these varieties of definitions of categories and subcategories of tasks in TBLT, there are varieties in the TBLT models for teaching language. Accordingly, it seems crucial for teachers to know their students, particularly their sociocultural backgrounds, well and choose the most suitable and efficacious tasks to help students acquire language. The next section explores the theoretical backgrounds of the TBLT model and identified concerns regarding the model.

\section{Backgrounds of TBLT}

\subsection{TBLT's connection to another learning theory: Sociocultural Theory and TBLT}

As it is already noted above, TBLT is a communication-oriented pedagogy that promotes interactions in L2 among learners (Nunan, 2004), and these tasks in TBLT need to be in the level that students basically can complete without teachers' help (Lee, 2000). This communication-oriented nature of learning, and the claim that tasks in TBLT need to be completed by students themselves has commonality with Vygotsky's sociocultural theory of learning. Sociocultural theory defines that learning happens in social interactions; therefore, for facilitating learning, implementing group works that require communications among learner is important (Vygotsky, 1978). Further, Vygotsky (1978) clarifies that teachers need to identify the zone of proximal development---the levels of tasks that learners are capable of doing without help and the levels of tasks that learners need help to complete---so teachers may offer the proper level of tasks. This matches with what some TBLT scholars claim important to consider when implement the pedagogy (Nunan, 2004; Lee, 2000). Given these commonalities between TBLT and sociocultural theory, and that more empirical researches are required to scientifically validate the effectiveness of TBLT as language pedagogy, sociocultural theory should be helpful as an additional theoretical framework to inquire about learning and learning processes in TBLT.

Sociocultural theory also provides a definition of the term "meaning". For instance, as Nunn (2001) claims, meaning exchange in TBLT is important for learning. Sociocultural theory defines that "meaning is determined by the relationship between the structure and interpretation of language and the context in which they appear" (Nunn, 2001). In other words, even if TBLT is used with the exact same tasks, meaning generated out of the tasks can be completely different because of the differences in the context and the structure. Accordingly, for implementing TBLT in the most effective way, sociocultural factors specific to where the pedagogy is implemented need to be considered as they are likely to influence how the meaning is determined while learners work on completing the tasks in TBLT.

\subsection{Concerns regarding TBLT}

Some scholars have indicated their concern that the TBLT model may neglect or hinder grammar acquisition, as the TBLT lacks sufficient amounts of form-focused, grammar-centered approaches (Burrow, 2008; Swan, 2005). However, it also should be noted that some of these criticisms about TBLT are based on misconceptions of the model (Dickinson, 2010). For instance, some scholars identify the task-based frameworks that are 
form-focused and/or grammar-based (Samuda, 2001; Skehan, 1996; Willis, 1996). This indicates that taking the TBLT approach does not necessarily mean NOT using form-focused grammar-based approaches for language learning. What really seems to be a limitation of the model is the fact that the TBLT has not been subject to a sufficient amount of empirical research to validate its effectiveness in language acquisition (Bruton, 2002; Sheen, 2003; Swan, 2005; Dickinson, 2010). Promoting empirical research on the model, therefore, would help scholars validate the effectiveness of TBLT and encourage teachers to use the model widely in their classrooms.

\section{TBLT's Applicability to University English Classrooms in Japan}

\subsection{Japan-specific sociocultural factors to be considered for implementing TBLT}

Some scholars indicate concerns that the model might not fit well with university classroom contexts in Japan. For instance, Burrows (2008) indicates his concern about implementing TBLT in Japan, namely that Japan's teacher-centered K-12 educational system shapes particular expectations among students regarding language learning processes. As a result, in English classrooms, Japanese university students are inclined to 1) "seldom initiate discussion", 2) "generally avoid raising new topics", 3) "rarely seek clarification", and 4) be "reluctant to volunteer answers" (Wadden, 1993, p.17). Given this sociocultural context, Burrow (2008) concludes that accomplishing English learning tasks with teammates that involve supplying one's own individual creative input and brainstorming could be challenging or might not be the most appropriate for Japanese university students' learning styles. Implementing TBLT even has a potential risk of demotivating university students from learning English because of its incompatibility with Japanese university students' learning styles (Burrow, 2008).

Similarly, Wicking (2009) also highlights an aspect of Japanese university students' class participation, namely that "one of the characteristics of Japanese university students that strikes many teachers is their great reluctance to participate in classroom communicative activities" (Wicking, 2009, p.251). These students are seen as shy, apathetic, or scared of making mistakes (Wicking, 2009). However, Wicking (2009) also points out that this does not necessarily mean that TBLT does not work well in university classrooms in Japan. Because these students are familiar with their teacher-centered pedagogies and are not comfortable with tasks that require their own creative input, "a focus on form at some points within a TBLT course will likely result in learners attaining much higher levels of accuracy, than if form-focused activities are absent" or asking them to work on tasks that require their own creative input (Wicking, 2009, p.252). Wicking (2009) also claims that as some students do not actively participate in classroom activities because of their fear of making mistakes, "[w]hen provided with time to think and construct language before engaging in a task, Japanese learners display greater confidence, which results in greater achievement" (Wicking, 2009, p.253). In short, Wicking (2009) claims TBLT might work well with Japanese university students if form-focused tasks are included and the participation structure is changed---students need to be provided with enough time to work on tasks so they are less 
likely to make mistakes in front of other classmates.

Given what Wicking (2009) claims, it seems possible to implement TBLT in university classrooms in Japan if 1) the tasks are modified to become more form-focused, and 2) teachers provide students with enough time to work on tasks to prevent them from making mistakes in front of their classmates.

Although Burrow (2008) claims that implementing TBLT has a potential risk of demotivating students as it is not suitable to their learning styles, Dickinson (2010) indicates that a recent study has found that in fact, NOT using communicative approaches such as TBLT in English classes results in demotivating university students in Japan. Dickinson (2010) further claims that "the use of non-communicative methods with an emphasis on grammar learning and examinations to be a significantly demotivating factor" (Dickinson, 2010, p.10). Accordingly, as long as tasks are modified so they fit well with Japan-specific sociocultural factors, implementing TBLT has the potential to motivate students to learn and attain high English competence rather than using non-communicative pedagogy.

\section{Conclusion}

This paper explores the TBLT model, examining particularly why it is replacing the PPP model worldwide, and considering what Japan-specific factors should be considered when implementing the model. The paper also explores the strengths and limitations of the model, especially what is necessary in the field to validate the effectiveness of the model. The needs regarding TBLT that have become clear are that more empirical researches are needed on the model. Further scientific validations of the effectiveness of the model based on empirical data will encourage teachers to widely use the model without concerns for the potential language fossilization among students.

For implementing TBLT, Burrow (2008) identifies another important point. He claims "[s]tudents must be made to recognize that learning an autonomous approach... is not a simple transmission of knowledge, but a collaboration as they attempt to express their own meanings for their own learning purposes" (Burrow, 2008, p.16). In other words, collaboration and interactions among students are necessary to take advantage of TBLT and acquire English. Given the communication-oriented nature of learning in TBLT, to ensure students learn properly using the model, inquiring into the following points seems necessary: 1) what tasks may promote what kind of interactions, and 2) what students learning will be as a result of these interactions.

Accordingly, in addition to the demand for further empirical researches on TBLT, inquiring into the relationships between the types of tasks and their impacts on students' learning under particular sociocultural contexts (i.e. such as university classrooms in Japan) seems to be a further avenue for investigation. 


\section{References}

Breen, M. (1987). Learner contributions to task design. In C. Candlin and D. Murphy (eds), Language Learning Tasks. Englewood Cliffs, NJ: Prentice-Hall.

Bruton, A. (2002). From tasking purposes to purposing tasks. ELT Journal, 56(3), 280-288. http://dx.doi.org/10.1093/elt/56.3.280

Burrows, C. (2008). Socio-cultural barriers facing TBL in Japan. The Language Teachers, $32(8), 15-19$

Dickinson, P. (2010). Implementing task-based language teaching in a Japanese EFL context. Unpublished MA thesis, University of Birmingham. Retrieved on Aug. $27^{\text {th }}$, 2014 from: http://www.birmingham.ac.uk/documents/college-artslaw/cels/essays/languageteaching/ dickinsonltm.pdf

Ellis, R. (2000). Task-based research and language pedagogy. Language Teaching Research, 4(3), 193-220. http://dx.doi.org/10.1177/136216880000400302

Ellis, R. (2003). Task-based language teaching and learning. Oxford: Oxford University Press.

Foster, P., \& Skehan, P. (1997). Task type and task processing conditions as influences on foreign language performance. Language Teaching Research, 1(3), 185-211. http://dx.doi.org/10.1177/136216889700100302

Hosseinni, H. S., \& Rahbar, M. (2012). A new trend in education: Task-based methodology for teachers/learners. 2012 International Conference on Management and Education Innovation IPEDR, 37, 253-256.

Lee, J. (2000). Tasks and communicating in language classrooms. Boston: McGraw-Hill.

Long, M. (1985). A role for instruction in second language acquisition. In K. Hyletenstan and M. Pienemann (eds.), Modeling and assessing second language acquisition. Clevedon, Avon: Multicultural Matters.

Long, M. (1989). Task, group, and task-group interactions. University of Hawaii Working Papers in ESL, 8, 1-26.

Nunan, D. (2004). Task-based language teaching. Cambridge: Cambridge University Press. http://dx.doi.org/10.1017/CBO9780511667336

Nunn, B. (2001). Task-based methodology and sociocultural theory. Retrieved on August $29^{\text {th }}$, 2014 from http://ltsc.ph-karlsruhe.de/Nunn.pdf

Richards, J., Platt, J., \& Weber, H. (1986). Longman Dictionary of Applied Linguistics. London: Longman.

Samuda, V. (2001). Guiding relationships between form and meaning during task performance. In M. Bygate, P. Skehan, \& M. Swain (Eds.) Researching pedagogical tasks: Second language earning, teaching and testing. Harlow, UK: Longman. 


\section{Macrothink}

International Journal of Education

ISSN 1948-5476

2014, Vol. 6, No. 4

Sheen, R. (2003). Focus-on-form: A myth in the making. ELT Journal, 57, 225-233. http://dx.doi.org/10.1093/elt/57.3.225

Skehan, P. (1996). A framework for the implementation of task-based instruction. Applied Linguistics, 17(1), 38-62. http://dx.doi.org/10.1093/applin/17.1.38

Skehan, P. (1998). A cognitive approach to language learning. Oxford: Oxford University Press.

Swan, M. (2005). Legislation by hypothesis: The case of task-based instruction. Applied Linguistics, 26(3), 376-401. http://dx.doi.org/10.1093/applin/ami013

Turuk, M. C. (2008). The relevance and implications of Vygotsky's sociocultural theory in the second language classroom. ARECLS, 5, 244-262.

Vygotsky, L. S. (1978). Mind in society: The development of higher psychological processes. Cambridge, MA: Harvard University Press.

Wadden, P. (1993). A handbook of teaching English at Japanese colleges and universities. Oxford: Oxford University Press.

Wicking, P. (2009). TBLT in Japan: Task-based language teaching and its effective implementation in the Japanese university classroom. OnCUE Journal, 3(3), 248-258

Willis, J. (1996). A framework for task-based learning. Harlow, UK: Longman.

\section{Copyright Disclaimer}

Copyright for this article is retained by the author(s), with first publication rights granted to the journal.

This is an open-access article distributed under the terms and conditions of the Creative Commons Attribution license (http://creativecommons.org/licenses/by/3.0/). 